\title{
Multiple intestinal atresia
}

INSERM

\section{Source}

INSERM. (1999). Orphanet: an online rare disease and orphan drug data base. Multiple intestinal atresia. ORPHA:2300

Multiple intestinal atresia is a rare form of intestinal atresia characterized by the presence of numerous atresic segments in the small bowel (duodenum) or large bowel and leading to symptoms of intestinal obstruction: vomiting, abdominal bloating and inability to pass meconium in newborns. 